\title{
Teacher Spiritualism: The Vocation Within
}

\author{
Luis Javier Pentón Herrera \\ Concordia University Chicago, Chicago, USA
}

\begin{abstract}
Ancient civilizations adopted an early education system that included religion as an integral part of its focus. For this reason, priests, monks, and other people of faith, were trusted with the important task of educating their community and instructing them in the values, beliefs, and norms of their society. As time passed, public education continued to evolve to keep up with the societal demands to the point that education and religion were not longer connected. Simultaneously, professionals in the education field have also changed and educators are no longer required to be people of faith. However, considering that the mission of education has remained the same, it would be unrealistic to consider teachers as unspiritual individuals regardless of their religious beliefs and affiliations. This paper explores the idea that educators are innate spiritual individuals who strive to perpetuate the norms, values and virtues of their society. In addition, this article presents the concept of teacher spiritualism as a contemporary reality of our teachers and our educational system.
\end{abstract}

Keywords: social improvement, spiritual education, teacher spiritualism, teacher empathy

\section{Background Information}

The idea behind this article originated from many personal and group reflections with colleagues about the past, present and future of education in our schools. The perpetual concern of educators about the future of our students and our society is a reality that we cannot control and the driving force behind our dedication and love for improving and educating everything and everyone around us. That mutual feeling of empathy and dedication were the main catalysts behind my reasoning for researching into the past of education. To my surprise, I found that educational systems in early civilizations thought of education as an opportunity to teach younger generations about their values, and trusted respected members in their society to carry out this duty. These members, who were religious, were expected to be dedicated and have faith in their traditions and beliefs in order to inculcate those same values to their pupils. The interdependent relationship between empathy and education is what guided this article and was the foundation of the initial idea for the concept of teacher spiritualism as a possible explanation for educators' shared values and missions since early civilizations.

\section{Introduction}

There are currently many fields of study that are more lucrative and provide a wider array of professional opportunities than education. However, major challenges such as lack of respect and appreciation, excessive paperwork, and continuous funding cuts (Strauss, 2015) have proven irrelevant for educators who stay in the

Luis Javier Pentón Herrera, M.Ed, M.S., M.Ed, Ph.D. Candidate, Graduate and Innovative Programs, Concordia University Chicago.

Correspondence concerning this article should be addressed to Luis Javier Pentón Herrera. 
field of education. Teaching has been described as an art and a science (Stones, 2012) and many would agree that teaching is a life-long vocation that some are born with, while others may find it along the way. Regardless of how or why individuals choose to become educators and stay in the education field, they feel a strong connection to the mission of improving their students' lives. In the teacher's mind, they facilitate knowledge that will ultimately be part of their students' success as future professionals.

The teaching field has evolved and changed many times since its inception, but one aspect that has remained intact is its focus on social improvement. According to the Alberta Teachers' Association (2015), educators have as a main focus to "pass on their accumulated culture and assist each student under their care in achieving self realization”. In this sense, teachers are advocates for social change and social empowerment. Perhaps, the concept of social service is a principle that attracts, consciously or unconsciously, many professionals to the field of education and keeps them in. The purpose of this article is to explore the concept of teacher spiritualism as it relates to vocation and social service. In addition, qualitative research is conducted to further explore this concept and its impact to education.

\section{Teaching as a Service Career}

Early education systems in ancient civilizations had two common characteristics: (1) the teaching of religion and (2) the teaching of cultural norms, values and traditions. Since religion was an integral part of education, people of faith (i.e. priests and monks) and philosophers were entrusted with educating the younger generations in the doctrines and values of their culture (History of Education, 2015). Throughout the centuries, education at religious institutions has evolved to include different subjects and evaluations, but people of faith have continued to serve as educators. Since the very beginning, education has been an opportunity for people of faith to be of service and to promote values and virtues.

Education has always been meaningful and it has always focused on promoting social values and norms to students (History of Education, 2015). Hence, early educators were, in its majority, people of faith trusted to carry their duty using their beliefs as their main resource. Since early beginnings, educators were meant to be spiritual because they needed to use their belief systems to shape their society and promote the acceptable code of conducts of their time. As times continued to change, some teachers remained people of faith-diverse faiths-but others did not. Before, education and religion were concepts closely intertwined, but this is no longer a reality. Today's education systems throughout the United States, both in the public and private sector, employ individuals from diverse walks of life and diverse religions and personal beliefs. However, can the teaching field still be considered a spiritual concept considering that the focus continues to be the same from the beginning of its history? It may not be too farfetched to assume that regardless of religious beliefs and affiliations, being an educator automatically entails being spiritual due to the mission and focus of this unique field.

\section{Teacher Spiritualism}

There is an abundance of literature classifying spiritualism as either a philosophical, scientific, or religious concept. However, for this article, the definition is used as a foundation to further explore and explain the concept of teacher spiritualism and does not necessarily agree nor disagree with any other perspectives. The National Spiritualist Association of Churches (NSAC) defines spiritualism as "the science, philosophy and religion of continuous life, based upon the demonstrated fact of communication, by means of mediumship, with 
those who live in the spirit world” (NSAC, 2002, p. 1). In this regard, spiritualism is perceived as a concept that defines the ability of someone to interpret, perceive, and communicate the essence of something or someone in order to keep it alive.

As previously stated, the mission of education has not changed throughout the years and civilizations. Likewise, teachers' primarily goal continues to be similar to that of those in the early education systems where people of faith were required to educate the younger generations in the values, virtues, and cultures of their society. Teachers continue to be the personification of knowledge and the facilitators who instill the accepted community codes to their pupils. They represent the bridge that perpetuates the ethic standards of their culture throughout the different generations and connects, through active communication, the ideas of their country's heritage. Regardless of time, teachers continue to be the recipient of the same values and beliefs as their predecessors, and they continue to pass that knowledge forward to their pupils.

Based on the information previously discussed, it could be debated that teachers are spiritual individuals who interpret, perceive, and communicate the essence of early education systems through today's education system in order to perpetuate the values, virtues, and cultures of their society. In other words, it can be debated that the teachers' innate ability to instill goodness in their students' lives, also known as vocation, automatically makes them spiritual beings. In addition, educators' vocation and spiritualism are the driving force behind their actions and commitment to service to a higher cause. For this reason, the following definition is proposed as an initial idea of teacher spiritualism.

Definition of "Teacher Spiritualism": The innate ability educators have, also known as vocation, to interpret, perceive, and communicate the essence of ancient and early education systems through today's education system in order to perpetuate the values, virtues, and cultures of their society.

\section{Similar Studies About This Topic}

There is little research regarding the impact of spirituality in education and whether the educators' awareness of spiritualism is directly connected to their performance. However, there are some studies that make reference to the positive relationship between the acknowledgement of spiritualism and education. Laura Jones, a Health and Wellness professor at Southern Oregon University, explains in her article the importance of spiritualism in education. In her own words, "if education is, as some have said, "learning to see with new eyes," then surely attending to spirituality, regardless of its existential benefits, is beneficial to the learning process!" (Jones, 2005, p. 4). In her article, Jones (2005) makes reference to the importance of understanding spiritualism as an individual identity that empowers educators and students alike.

Rachel Kessler, director of The Institute for Social and Emotional Learning, and author of The Soul of Education, also explains the importance of spiritualism in teachers' daily practices. In her book, Kessler (2000) approaches spirituality in education as an ability that educators can develop to resolve deeply entrenched conflicts within themselves and others, and to feel respect where once there was hate and mistrust. From this perspective, spiritualism in education is used to explain educators the importance of finding compassion and empathy in their actions in order to better serve their students and be better human beings. The concept of teacher spiritualism presented in this paper and Kessler's analogy are somewhat similar as they seek to explain the impact awareness of spiritualism has in the teaching practices of educators. 


\section{Survey Findings}

A qualitative survey was conducted for this article with the purpose of analyzing the inner perception of teachers about what they do and how they feel about teaching. The qualitative survey was voluntary and it was conducted at a public school. All teachers were notified and only 41 chose to participate in this survey. Also, two university professors were asked to complete the survey and they agreed.

Since the word "spiritualism" is generally associated with religion, many educators would not agree with the definition of teacher spiritualism and the wording used in it. For this reason, the survey conducted for this research asked teachers to share their thoughts about this definition without mentioning religion or the idea of educators as innate spiritual individuals in the survey. A total of 43 teachers completed the survey, 41 high school teachers and two university professors. The three questions asked in the survey were:

(1) Do you consider yourself a religious person?

(2) Do you identify your vocation to be an educator as an (unconscious or conscious) individual mission to be of service to a higher cause?

(3) Do you agree with this statement? Educators have an innate ability, also known as vocation, to interpret, perceive, and communicate the essence of ancient and early education systems through today's education system in order to perpetuate the values, virtues, and cultures of their society.

The results in Figure 1 reflect the results for the first question. These results show that the majority of teachers who took the survey are, at least, somewhat religious, and the minority is a little religious or not religious at all.

Do you consider yourself a religious person?

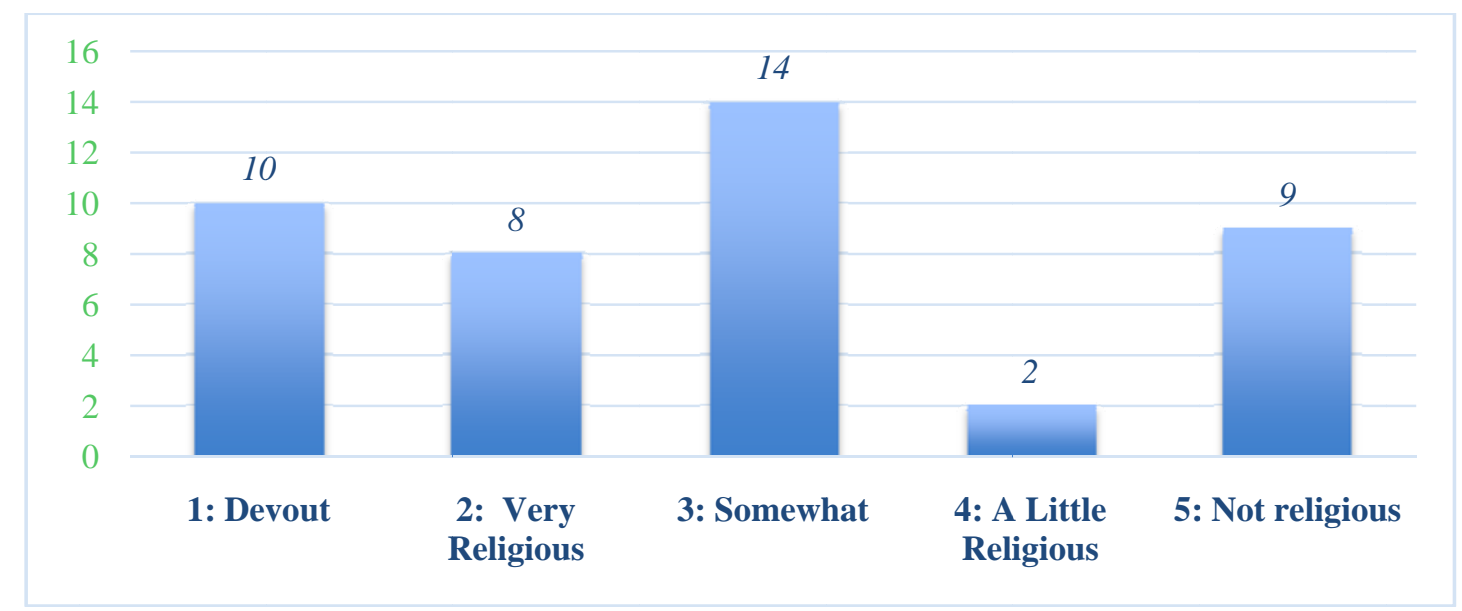

Figure 1. Religious beliefs.

The results in Figure 2 reflect the results for the second question. These results show that the majority of teachers believe their vocation is the driving force behind their individual mission to be of service to a higher cause. A total of 34 respondents answered positively to the question while 9 respondents answered negatively.

Do you identify your vocation to be an educator as an (conscious or unconscious) individual mission to be of service to a higher cause? 


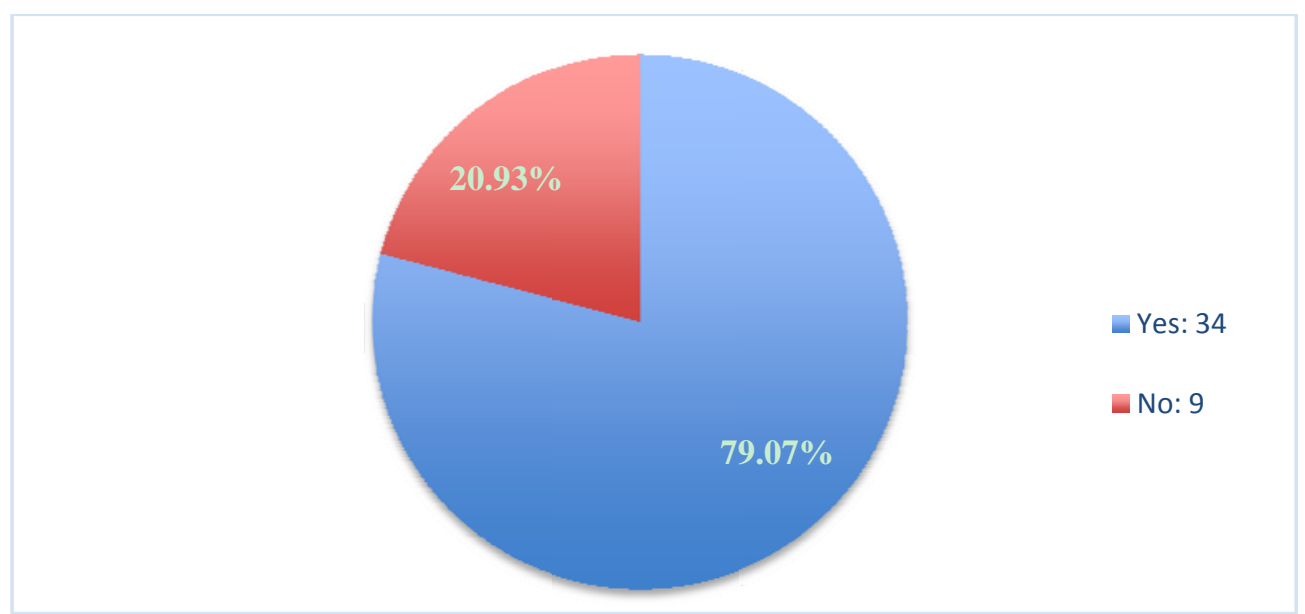

Figure 2. Vocation and higher purpose.

The results in Figure 3 reflect the results for the third question. These results show that the majority of teachers agree with the statement that identifies the definition of teacher spiritualism without knowing what the statement stands for.

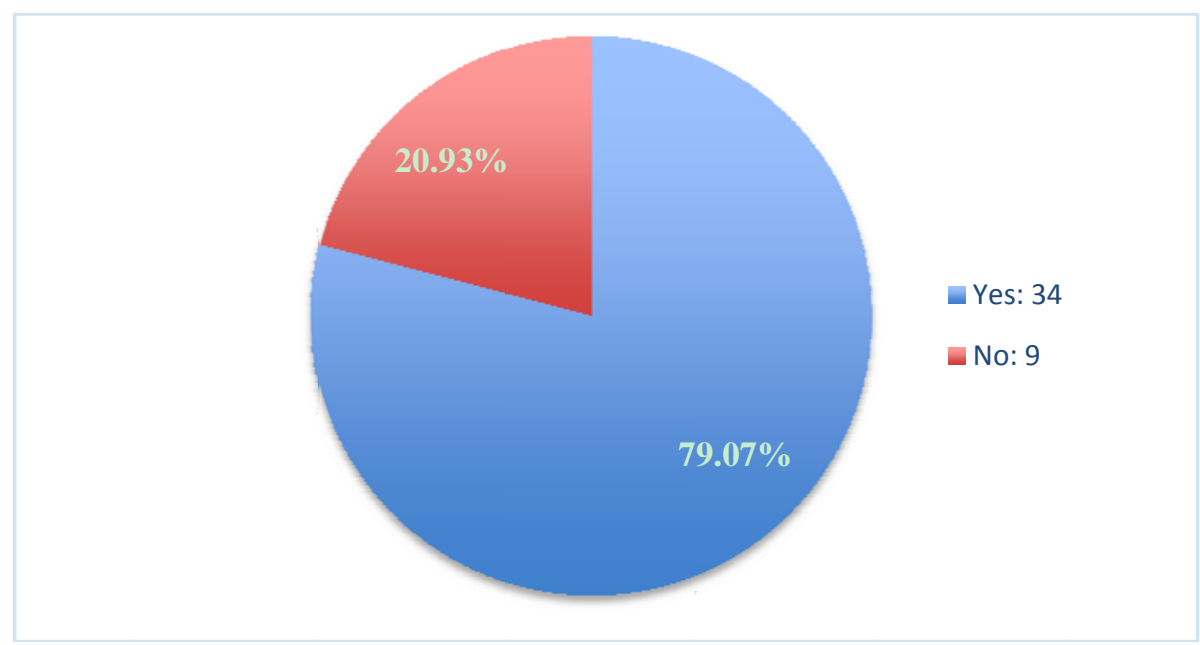

Figure 3. Teacher spiritualism definition.

Do you agree with this statement?

Educators have an innate ability, also known as vocation, to interpret, perceive, and communicate the essence of ancient and early education systems through today's education system in order to perpetuate the values, virtues, and cultures of their society.

An interesting finding in this survey is that the same amount of teachers who identified themselves as "not religious" $N=9$, was the same amount of educators who did not agree with the Teacher Spiritualism concept and did not agree with having a mission to serve for a higher cause. These results are very interesting because it disagrees with the initial statement that all educators should be considered spiritual individuals who believe in their mission of impacting society and having a mission of higher purpose. However, it invites to continue researching to whether there is a connection between those educators who agree with the teacher spiritualism definition, consider themselves at least a little religious, and believe that their vocation is an opportunity for them to serve to a higher cause. Future research about this topic could address the reason behind teacher 
spiritualism and the connection between the beliefs of serving for a higher cause and whether or not teachers identify as religious individuals. In addition, future research could also research the connection between the acceptance of teacher spiritualism as a concept and the performance of educators in the classroom.

\section{Final Thoughts and Conclusion}

The idea behind teacher spiritualism originated from many conversations with colleagues and readings about the purpose, mission, and vision of educators in today's society. In a world where children act and feel like adults, teachers are left to improvise approaches and situations where they can reach their students academically and personally in order to perpetuate the norms and instill the values students need to learn to be successful in their society. Since education is both an art and a science, there are some events and situations that can be approached using conventional methods, but other times, educators have to rely on their innate ability and vocation to stay focused in their mission.

The definition of teacher spiritualism is introduced as a concept that seeks to explain a possible approach educators use to educate their students. This article debated that educators use the essence of teacher spiritualism as a tool to reach deep inside them and connect to the true meaning of education and what it stands for. As the survey showed, the exact amount of teachers who identified themselves as not religious also disagreed with the statement of teacher spiritualism and with the idea that teaching has a higher purpose. This article invites researchers to further explore the concept of teacher spiritualism and its relevance to modern education and to today's educators.

\section{References}

History of Education. (2015). Funk \& Wagnalls New World Encyclopedia, 1, 1.

Jones, L. (2005). What does spirituality in education mean? Journal of College and Character, 6(7), 1-7.

Kessler, R. (2000). The soul of education: Helping students find connection, compassion, and character at school. Alexandria, VA: ASCD.

National Spiritualist Association of Churches (NASC). (2002). Spiritualism: Declaration of principles, interpretations, and definitions. Retrieved from https://www.nsac.org/literature/Declaration\%20of\%20Principles,\%20Interpretation,\%20and\%20Definitions.pdf

Stones, E. (2012). Readings in educational psychology. London: Routledge.

Strauss, V. (2015). Why so many teachers leave and how to get them to stay. The Washington Post News. Retrieved from https://www.washingtonpost.com/news/answer-sheet/wp/2015/06/12/why-so-many-teachers-leave-and-how-to-get-them-to-s tay/

The Alberta Teachers' Association (ATA) website. (2015). Nature of teaching and teaching as a profession. Retrieved from http://www.teachers.ab.ca/About\%20the\%20ATA/Governance/PolicyandPositionPapers/Position\%20Papers/Pages/Nature\% 20of\%20Teaching\%20and\%20Teaching\%20as\%20a\%20Profession.aspx 